\title{
HYPOTHETICAL ACCIDENT IN POLISH NUCLEAR POWER PLANT. WORST CASE SCENARIO FOR MAIN POLISH CITIES
}

\author{
HIPOTETYCZNA AWARIA W POLSKIEJ ELEKTROWNI JĄDROWEJ. \\ NAJGORSZY SCENARIUSZ DLA DUŻYCH POLSKICH MIAST
}

\begin{abstract}
Poland is under threat of potential accidents in nuclear power plants located in its close vicinity, in almost all neighboring countries. Moreover, there are plans to establish a new nuclear power plant in Polish coast. In this paper the analysis of atmospheric transport of radioactive material released during a potential accident in the future nuclear power plant is presented. In the first part of study transport of radioactivity as seen from the long time perspective is analyzed. This involves trajectory analysis as a tool for describing the statistics of air pollution transport pattern and screening the meteorological situations for episode studies. Large sets of meteorological data for selected episodes were stored as a result of this process. Estimation of risk includes both analysis of the consequences and probability analysis of an occurrence of such situation. Episodes then were comprehensively studied in the second phase of the study, using the Eulerian dispersion model for simulation of atmospheric transport of pollutants. This study has proven that the time needed for reaction in case of (hypothetical) accident is enormously short.
\end{abstract}

Keywords: nuclear power plant, modeling, atmospheric transport, meteorology

\section{Introduction}

The Chernobyl accident in 1986 showed that the countries which do not have Nuclear Power Plant (NPP) and are located far away from the NPP can also be seriously affected by nuclear accidents. The examples of such countries are Norway and Poland.

For Norway, there here have been several studies with analysis of worst case scenario in case of accident outside the country. One of the main threats for Norway is a possibility of an accident in Kola NPP and different nuclear installations in the region. However, accidents in other nuclear power plants in Europe, e.g. Sellafield and Leningrad (Leningrad NPP is located in close vicinity of city of St. Petersburg, formerly known as Leningrad) can seriously affect Norwegian territory and must also be taken into account. Analysis and assessment of long-distance consequences of a hypothetical nuclear accident in an NPP located in the Kola peninsula was a subject of the joint project between the Norwegian Radiation Protection Authority (NRPA), Norwegian Meteorological Institute (NMI) and Institute for Energy Technology (IFE), which was performed in 1996. The NMI's role in

\footnotetext{
${ }^{1}$ Institute of Meteorology and Water Management - National Research Institute, ul. Podleśna 61, 01-673 Warszawa, Poland, phone +48 2256941 34, fax +48 2256943 56, email: andrzej.mazur@imgw.pl
} 
the project was the analysis of long-range atmospheric transport and deposition of radioactive material emitted from a potential accident in Kola NPP [1]. The main focus in this approach was atmospheric transport of emitted particles with different sizes and densities. A similar was initiated by NRPA in 2009, this time for Leningrad NPP as a source of potential radioactive release. The main goal of the project was the evaluation of potential consequences for Norway caused by a hypothetical accident. The NMI's role in the project was again limited to analysis of atmospheric transport and deposition of radioactive debris, including probabilistic approach to this issue. It can be stressed that similar assessments and studies has been prepared for Denmark, namely Copenhagen [2], and for Kola peninsula [3, 4].

A hypothetical accident in any NPP outside Polish territory can affect Poland in the similar way, but with even more serious consequences, because of the larger population in Polish cities. A serious nuclear accident in Fukushima I NPP in Japan, which happened recently in 2011, proves that such accidents may occur and are not only hypothetical. In this particular case, the air masses reached western coast of USA in five days, and eastern coast - in nine days. In two weeks the air masses hit Europe, approaching from west. So, the important parameter is both air flow (wind) velocity/direction and the strength of a release. Moreover, for several years Polish Ministry of Energy has been issuing plans of building of an NPP to be located in Polish territory over the coast of the Baltic Sea (possible location: Zarnowiec close to Gdansk). Therefore, in this study the worst case scenario for Poland assuming an accident in such NPP (identified later in this paper as Zarnowiec Nuclear Power Plant) was investigated. It is organized and reported in two parts. In the first phase, the method for finding the worst case meteorological scenario based on the trajectory analysis is described and discussed, as well as the obtained results. These results include the selection of the meteorological conditions and dates for the Eulerian dispersion model simulations [5]. In the second part of the research this model was used with meteorological scenarios (selected in the first phase) to calculate the corresponding concentration and deposition of the radioactivity over the Polish territory, in particular over the biggest Polish cities. Results will be presented in the next part of the study.

\section{Methodology - trajectory analysis}

There is a risk of serious threat to Poland in case of an accident in Zarnowiec NPP. This risk is a combination of probability, that radioactive debris from the accident would arrive to big cities, and the possible consequences of this arrival, that in turn would depend on the local conditions. The contribution to the evaluation of the risk related to a possible accident is limited to a probability issue and selection of the worst case scenarios from the meteorological point of view.

A meteorological nature of the atmospheric transport in case of an accident is very episodic. It means that it is the current weather at the time of the accident which determine the direction and the speed of the radioactive material transport in the air, as well as the rate of its removal. For a given weather situation, a specific location can get the full impact from the accidental release, although the statistical probability of the outcome can be relatively low. This means that the consequences of a real accident might have a quite different real arrangement compared to probabilistic estimations. One must remember that although the probability may be low, the risk and consequences of such an incident can be 
substantial. This is an important lesson to be learned from the Chernobyl and Fukushima accident. Thus, the results of the probability estimations should not be "over-interpreted".

There are two main questions which have to be answered very fast in case of a real accident. The first one and the most important is: will a radioactive cloud reach the location of interest? When the answer is yes, the follow-up question is: how soon will the radioactive cloud come to the location of interest? In a real situation the answers to these questions are based on operational model runs and trajectory calculations in forecast mode. The decision makers responsible for the management of the crisis situation will know the answer shortly after the alert.

In preparedness or planning phase, when the accident has not happened yet, but there is a chance for it at a given nuclear installation, the similar questions as above can be asked, but this time in the probabilistic mode. The main issue of interest in such a situation is the probability of radioactive debris coming to specific location in Poland in case of a hypothetical accident in a given NPP. Theoretically, this issue and any additional questions specified in the next section can be answered by the model runs with very long term historical meteorological data. However, this approach is presently rather difficult because of very long computational time and large computer memory needed. Therefore, an approach based on trajectory analysis was chosen, which proved to be successful during the earlier Finnish study of a hypothetical radioactive release from Leningrad NPP [6].

An important outcome of the trajectory analysis, beside the probability statistics is a selection of the meteorological situations for the "worst case" scenarios. For these selected situations the dispersion model was applied to simulate an atmospheric transport and deposition of radioactive debris to selected receptor points (cities) in Poland, as described in the second part of the study. The results of these simulations compensate, to some extent, the uncertainty related to probabilistic trajectory estimations.

From the meteorological perspective the problem can be formulated in three main questions, assuming that the accident at Zarnowiec NPP can happen at any time:

- What will be the probability of arrival of the radioactive cloud to specific locations in Poland in case of a hypothetical accident in Zarnowiec NPP? To assess this probability, one should calculate a number trajectories of the total amount released hit Warszawa, Krakow, etc.

- What will be the shortest and an average arrival time of the cloud to specific locations in Poland?

- Which meteorological situations can be selected for the "worst case" meteorological scenarios for Poland?

In order to solve the problem and answer the above questions the analysis of trajectories was used. The approach was limited to meteorological and dispersion aspects and thus mostly focused on the probability part of the problem. For example, the issues of the probability of an accident to occur at Zarnowiec NPP (i.e. the safety and reliability of future installations) and those related to the source conditions (for example, chemical composition of a release) are not discussed in this study.

The area in which meteorological data were available and trajectories were released is covered by the COSMO grid system. This grid system has the resolution of $28 \mathrm{~km}$ in rotated longitude-latitude projection. It consists of $175 \times 160$ nodes in $\mathrm{x}$ - and y-direction, respectively, and is shown in Figure 1. This domain is extended in comparison to standard operational COSMO domain to cover not only the location of Zarnowiec NPP and Poland, but also other European nuclear power plants for future use with reasonable edge. 


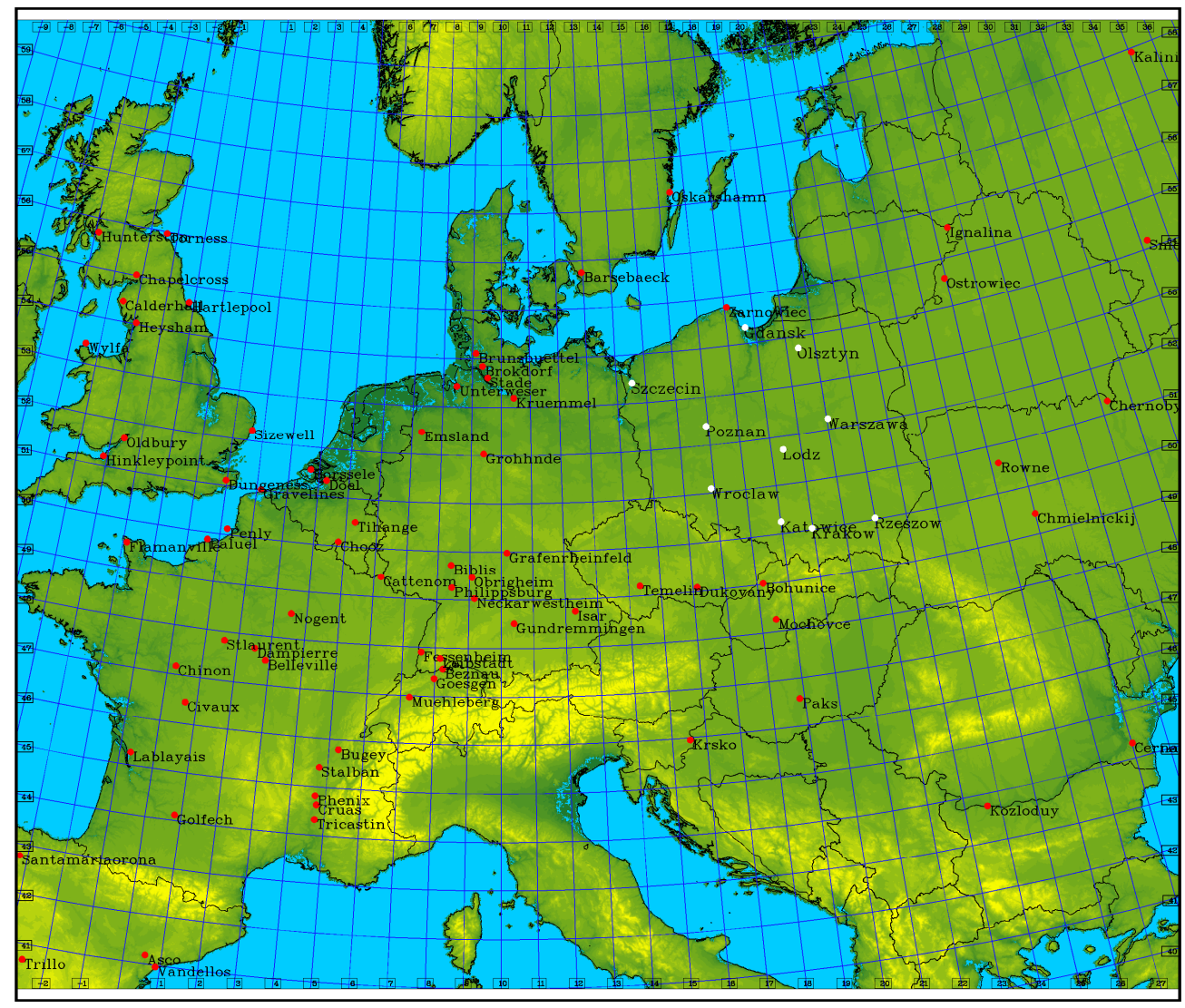

Fig. 1. Extended computational domain of the COSMO model and of dispersion model at IMWM. This domain is covered by the grid with $28 \mathrm{~km}$ resolution which was used for the trajectory calculations. Red dots indicate locations of main nuclear power plants in Europe (active, turned off and planned), including the planned Zarnowiec NPP. White dots represent locations of ten Polish cities selected as receptor points

In this approach, the trajectory analysis has been performed in two steps:

Step 1. The ten-year period of meteorological data (2005-2014) was compiled with assured homogeneous characteristics in time. This set of data - results of computations of global meteorological model GME (Global Model Ersatz, computed at DWD, Germany) is currently used at IMGW as an initial and boundary conditions for operational weather forecast, using COSMO model (regional meteorological model of Consortium for Small-Scale Modeling [7, 8]). The main part of data used included instantaneous three-dimensional wind fields every three hours at ten pressure levels from 1000 up to 200 by $100 \mathrm{hPa}$ (and with additional level $950 \mathrm{hPa}$ ). In the similar previous investigations [1] only a single level of $925 \mathrm{hPa}$ (roughly corresponding to $600 \mathrm{~m}$ height above the terrain and representing the level of the bulk transport of pollutants in the atmospheric boundary layer, $\mathrm{ABL}$ ) was chosen for simulations, making in fact the problem two-dimensional. 
However, to have a complete picture of trajectories' dispersion, full 3-D wind fields of three components (zonal, meridional and vertical) were applied to carry-out modeling.

Step 2. The compiled wind fields were used to compute 10 days long, forward trajectories originating at the Zarnowiec NPP at mentioned level $925 \mathrm{hPa}$, which can be assumed, in general, as an average effective emission height [5] of contaminants in a hypothetical emission incident. One trajectory was released every third hour (at 00, 03, 06, 09, 12, 15, 18, and 21) during the entire ten-year period. Time step between the consecutive points on each trajectory was 4 minutes, to be sure that the distance between two consecutive points is shorter than the grid square size - $28 \mathrm{~km}$. All together 29200 trajectories were released for the period 2005-2014. Methodology for trajectory calculation was extended to three-dimensional case (see also $[9,10])$.

\section{Results - calculation of trajectories}

The main goal of the trajectory analysis in this study was the selection, from the meteorological point of view, of the worst case scenarios for a hypothetical accident in Zarnowiec NPP. The selection of the meteorological worst case scenarios was based on the following results presented in this Section:

- Probability of arrival maps and more precisely, the probability of each model grid square to be hit by or passed by the trajectory of an air parcel starting from Zarnowiec NPP

- Maps of minimum travel time from Zarnowiec NPP to each model grid cell

- Maps of average travel time from Zarnowiec NPP to each model grid cell

- Analysis of trajectories arriving to selected Polish cities

- Statistical analysis of travel time from Zarnowiec NPP to selected Polish cities

\section{Probability maps}

Overall 29200 trajectories were released from the location of the Zarnowiec NPP in the considered 10-year period. An exemplary trajectory is shown in Figure 2. Each released trajectory passed the grid square including Zarnowiec NPP and the calculated probability for this grid was equal to one - the absolute maximum value for the entire model area. A map with the probability of a trajectory arrival to each grid cell of the model domain is shown in Figure 3. A map - focused on the Polish territory - with the probability of arrival to each grid cell located in Poland is also shown in Figure 3.

The computed probability of arrival depends on the length of the trajectories. In general, the probability of arrival slightly increases with the length of the trajectory, but the results of earlier experiments indicate that for trajectories longer than eight days the probability of arrival does not change much. However, to maintain consistency of selected meteorological conditions, full ten-days long trajectories were used in the computations. 


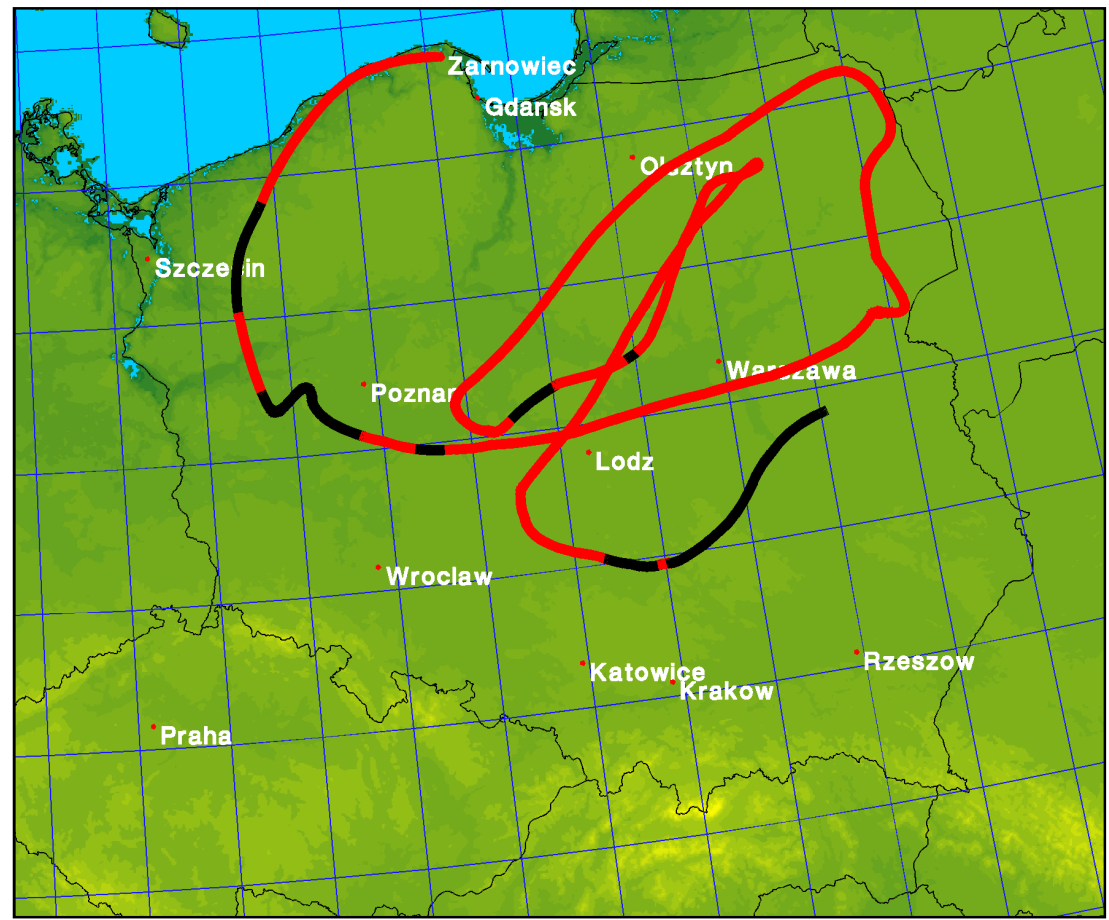

Fig. 2. An example of trajectory, released from Zarnowiec NPP. The red segments on the trajectory are those with dry transport, whereas the black segments of the trajectory are those affected by precipitation. The trajectory with the longest travel time (240 hours, start: July $29^{\text {th }}, 2008,00: 00$ UTC) over Poland is shown in the example

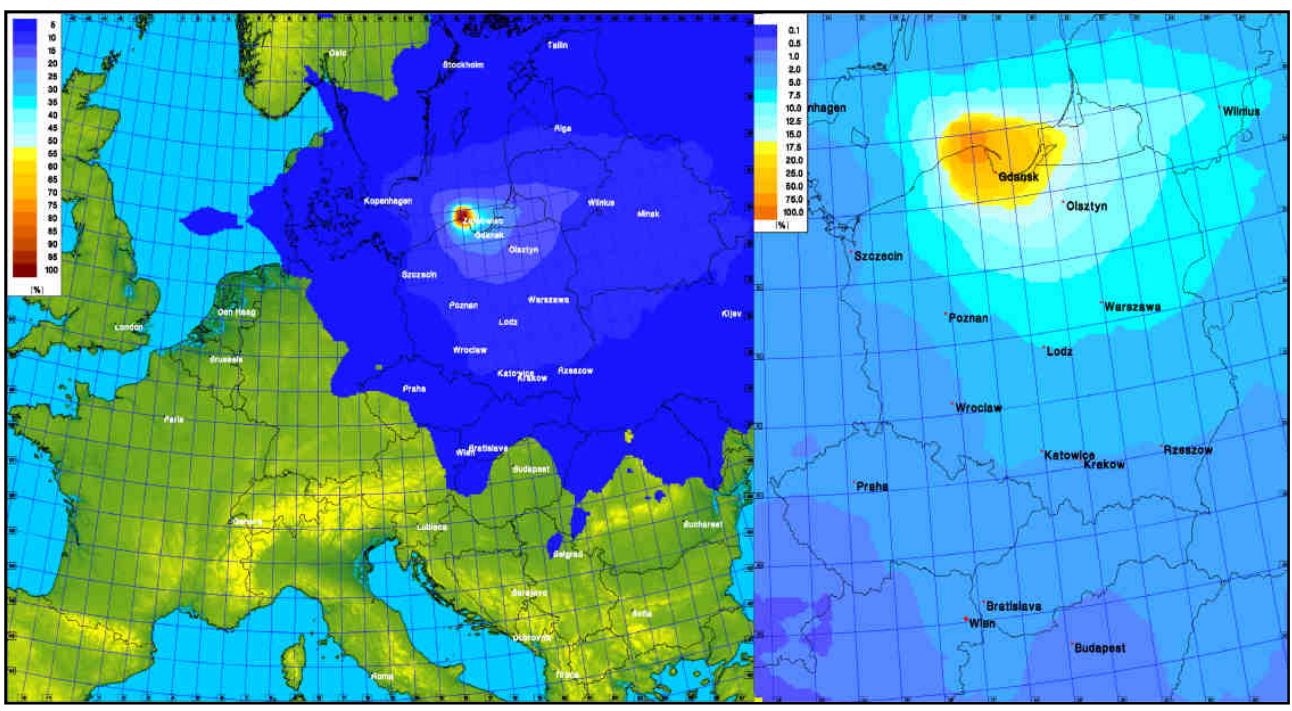

Fig. 3. Probability maps of trajectory arrival to each grid square of the model domain (left) and to each grid square located in Poland (right); calculated on the basis of trajectory analysis 


\section{Analysis of transport time}

The probability maps shown in Figure 3 gives the answer to the first question posed above: "what will be the probability of arrival of the radioactive cloud to specific locations in Poland in case of a hypothetical accident in Zarnowiec NPP?" Of course, since Zarnowiec NPP is planned to be located in Poland, this probability, overall, is quite high for most of the Polish territory. Thus, the next and maybe even more important question to be answered is: "what will be the shortest and the average arrival time of the cloud to specific locations in Poland?" To answer this question, the shortest travel time was computed in three steps. First, the number of points on the trajectory, released at Zarnowiec NPP and reaching a particular grid, was calculated. On each trajectory, the counting started from the second point to omit the exact location of Zarnowiec NPP (first point). Then the number of the counted points was multiplied by the time step on the trajectories $(4 \mathrm{t}=15 \mathrm{~min})$ to calculate travel time. In this procedure other (except the first one) trajectory points reaching this specific grid were not taken into account. Each calculated travel time was stored for each grid. Finally, the average arrival time was calculated for each grid and the shortest travel time was selected from all stored travel times.

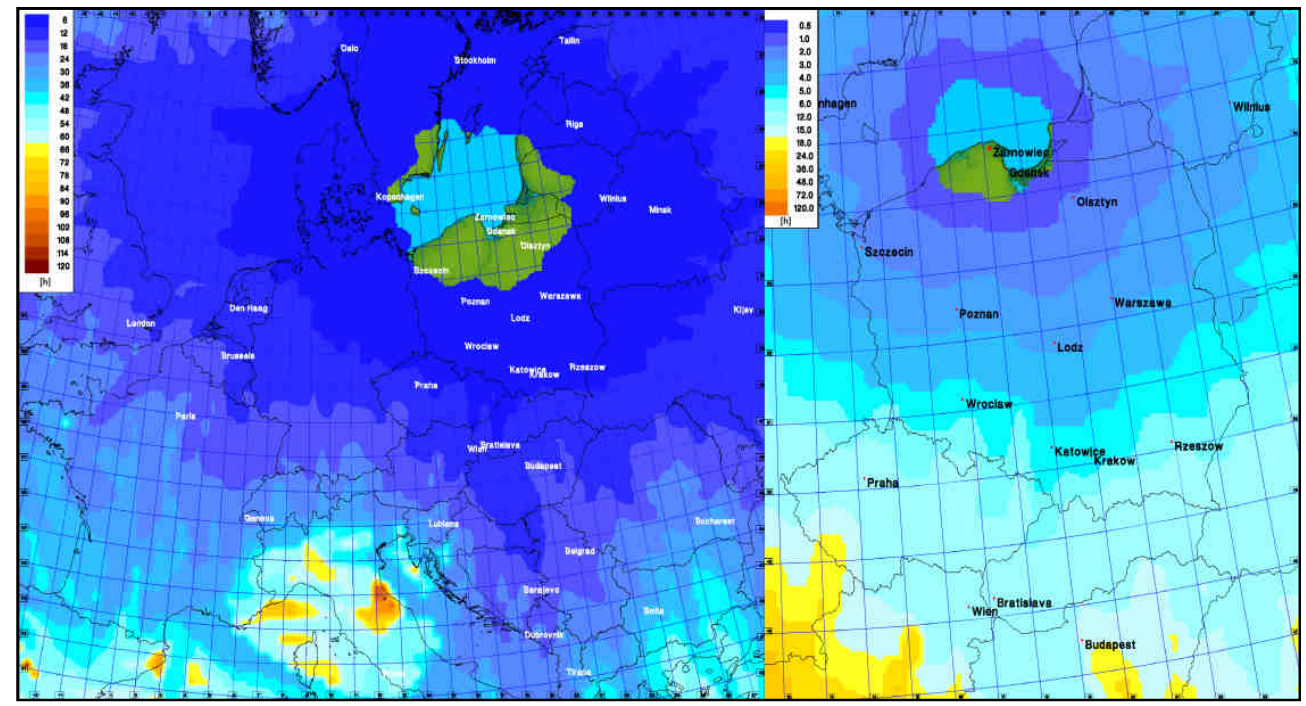

Fig. 4. Map of the shortest arrival time to each grid square in the model domain (left) and map of the shortest arrival time to each grid square located in Poland (right). Transparent areas (with no color assigned) have a value of travel time roughly below 3 hours (left) and 30 minutes (right chart)

In turn, a map with the shortest arrival time to each grid of the area of interest (extended COSMO domain) is shown in Figure 4 together with a more detailed map of the shortest arrival time to each grid located in Poland. Trajectory released from the Zarnowiec NPP with the longest travel time (240 hours) over Poland is shown in Figure 2. The contour lines of the shortest arrival time are quite regular for the short travel times up to approximately 24 hours. For longer times, the shape of contour lines became rather irregular. 
One conclusion from the maps presented in Figure 4 is that, in the worst case scenario the radioactive cloud from the accident in Zarnowiec NPP can reach almost any point located in Poland within 6 hours. It means that time for overall preparation is very limited.

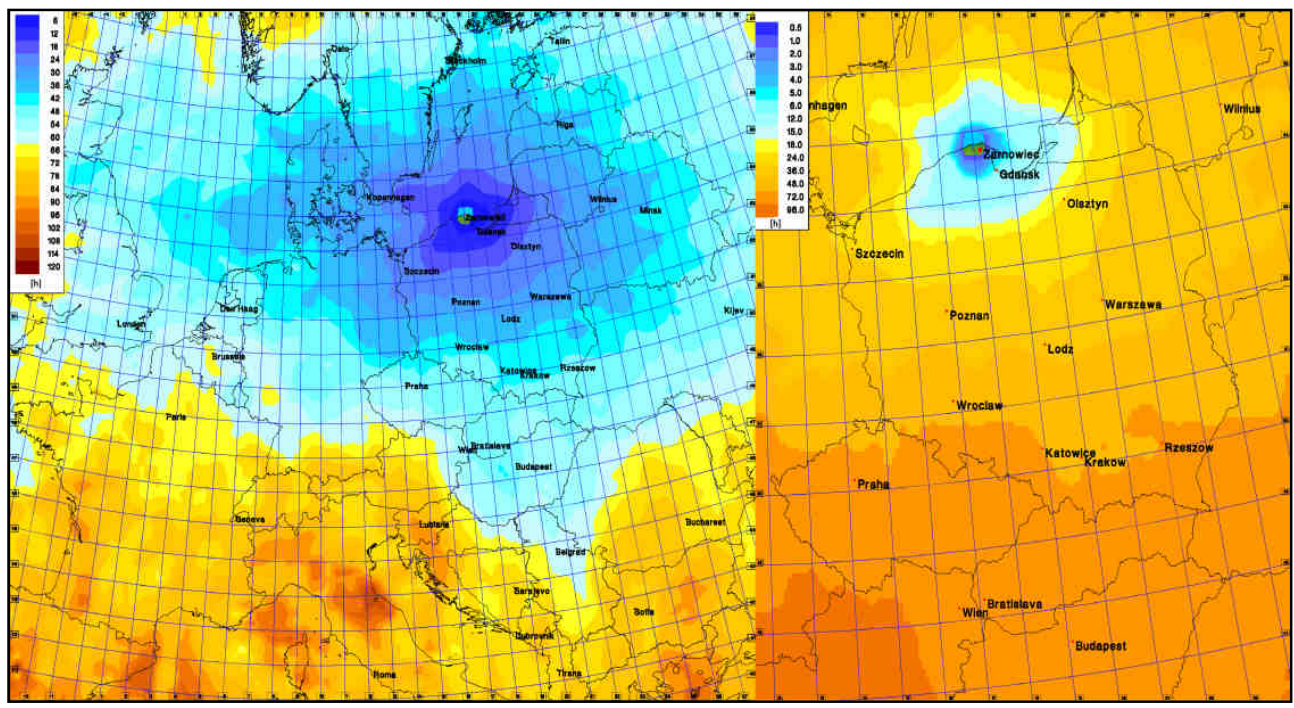

Fig. 5. Map of average arrival time to each grid square in the model domain (left) and map of average arrival time to each grid square located in Poland (right). Transparent areas (with no color assigned) have a value of travel time below 3 hours (left) and 30 minutes (right chart)

A map with the average arrival time to each grid square of the area under consideration is shown in Figure 5. A more detailed map with the average arrival time to each grid located in Poland is also shown in Figure 5. The distribution pattern of the average arrival time is quite similar to the distribution pattern of the shortest arrival time, except that the average arrival time is much longer. For almost all grid cells located in Poland the average arrival time is approximately 48 hours ( 2 days). It means, that for the average conditions, there is much more time for the preparation in case of an accident in Zarnowiec NPP, than in case of the worst conditions. However, the aim of this study is to consider cases with worst possible conditions.

\section{Detailed results for main Polish cities}

A part of the trajectory analysis was performed for Polish cities, taking into account the large population density there. Ten cities and corresponding receptor grid squares were selected, representing the largest populations and different locations in Poland: Gdansk, Olsztyn, Szczecin (all located in the northern part of the country), Poznan, Warszawa, Lodz (central Poland), and Wroclaw, Katowice, Krakow and Rzeszow (located in the southern part of Poland). Locations and populations are presented in Table 1. The locations of selected cities are also shown in Figure 1.

Of all the released trajectory for each city (receptor site) were counted all incoming trajectories, their number, the probability of arrival, the shortest and the average time to 
reach the grid, and percentage of trajectories with the travel time (to the city) shorter than a specific value. These results are summarized in Table 2 .

Table 1

Name, location and population of Polish cities selected for analysis of the worst case scenario for hypothetical accident in Zarnowiec NPP

\begin{tabular}{|c|c|c|c|c|}
\hline Receptor city & $\begin{array}{c}\text { Population } \\
\text { (inhabitants) }\end{array}$ & $\begin{array}{c}\text { City area } \\
{\left[\mathbf{k m}^{2}\right]}\end{array}$ & $\begin{array}{c}\text { Geographical } \\
\text { co-ordinates }\end{array}$ & $\begin{array}{c}\text { Distance } \\
\text { to the source [km] }\end{array}$ \\
\hline Warszawa & 1716855 & 516.9 & $52^{\circ} 14^{\prime} \mathrm{N}, 21^{\circ} 01 \mathrm{E}$ & 344 \\
Lodz & 768755 & 293.2 & $51^{\circ} 47^{\prime} \mathrm{N}, 19^{\circ} 28^{\prime} \mathrm{E}$ & 349 \\
Krakow & 755050 & 327.0 & $50^{\circ} 04^{\prime} \mathrm{N}, 19^{\circ} 56^{\prime} \mathrm{E}$ & 540 \\
Wroclaw & 634893 & 292.8 & $51^{\circ} 06^{\prime} \mathrm{N}, 17^{\circ} 02^{\prime} \mathrm{E}$ & 415 \\
Poznan & 570352 & 261.8 & $52^{\circ} 24^{\prime} \mathrm{N}, 16^{\circ} 55^{\prime} \mathrm{E}$ & 275 \\
Gdansk & 435830 & 262.0 & $54^{\circ} 22^{\prime} \mathrm{N}, 18^{\circ} 38^{\prime} \mathrm{E}$ & 60 \\
Szczecin & 407811 & 301.0 & $53^{\circ} 25^{\prime} \mathrm{N}, 14^{\circ} 35^{\prime} \mathrm{E}$ & 275 \\
Katowice & 317316 & 164.7 & $50^{\circ} 15^{\prime} \mathrm{N}, 19^{\circ} 0^{\prime} \mathrm{E}$ & 507 \\
Rzeszow & 179455 & 116.4 & $50^{\circ} 02^{\prime} \mathrm{N}, 22^{\circ} 00^{\prime} \mathrm{E}$ & 591 \\
Olsztyn & 171803 & 88.3 & $53^{\circ} 47^{\prime} \mathrm{N}, 20^{\circ} 30^{\prime} \mathrm{E}$ & 191 \\
\hline
\end{tabular}

Statistics of trajectories arriving to selected Polish cities from Zarnowiec NPP

\begin{tabular}{|c|c|c|c|c|c|c|c|c|c|c|}
\hline \multirow{2}{*}{ Receptor city } & \multicolumn{3}{|c|}{$\begin{array}{c}\text { Travel time } \\
\text { [hours] }\end{array}$} & \multicolumn{5}{c|}{$\begin{array}{c}\text { Travel time not longer than [hours] } \\
\text { Pct. of total amount of trajectories }\end{array}$} & $\begin{array}{c}\text { Sum } \\
{[\%]}\end{array}$ & $\begin{array}{c}\text { Sum } \\
{[-]}\end{array}$ \\
\cline { 2 - 10 } & Min. & Mean & $\mathbf{2 4}$ & $\mathbf{4 8}$ & $\mathbf{7 2}$ & $\mathbf{9 6}$ & $\mathbf{1 2 0}$ & $\mathbf{1 4 4}$ & & \\
\hline Gdansk & 0.1 & 4.3 & 29.8 & 0.5 & 0.3 & 0.2 & 0.2 & 0.2 & 31.2 & 9110 \\
Olsztyn & 1.1 & 17.3 & 10.2 & 1 & 0.6 & 0.4 & 0.4 & 0.2 & 12.8 & 3738 \\
Szczecin & 2 & 24.3 & 3.7 & 0.6 & 0.3 & 0.3 & 0.2 & 0.1 & 5.2 & 1518 \\
Poznan & 2.3 & 29.7 & 3.9 & 0.9 & 0.4 & 0.5 & 0.3 & 0.1 & 6.2 & 1810 \\
Warszawa & 2.5 & 28.9 & 5.3 & 1.3 & 0.7 & 0.3 & 0.5 & 0.2 & 8.2 & 2394 \\
Lodz & 2.5 & 33.1 & 4.5 & 1.5 & 0.8 & 0.5 & 0.4 & 0.3 & 7.9 & 2307 \\
Wroclaw & 3.9 & 46.3 & 1.9 & 1 & 0.7 & 0.6 & 0.5 & 0.2 & 4.8 & 1402 \\
Katowice & 4 & 38.9 & 2.3 & 1 & 0.8 & 0.3 & 0.3 & 0.2 & 4.9 & 1431 \\
Krakow & 4.3 & 41.4 & 1.7 & 0.8 & 0.5 & 0.3 & 0.3 & 0.2 & 3.7 & 1080 \\
Rzeszow & 4.9 & 46.4 & 2 & 1.1 & 0.9 & 0.5 & 0.4 & 0.3 & 5.2 & 1518 \\
\hline
\end{tabular}

In Table 2 column marked as "Sum [\%]" represents the total probability of trajectory's arrival to a selected city, and the "Sum [-]" is the total amount of trajectories arriving to the city.

Number of incoming trajectories and the probability of reaching the city are the highest for Gdansk and the lowest for Wroclaw. One can notice an obvious and understandable gradient in north-south direction of these statistics, as well as the relatively large differences in the shortest arrival time to Gdansk and to Rzeszow. It is also worth noting that the largest average arrival time appeared to Rzeszow, which is related to the probability distribution of arrival trajectories (see next section). For each selected city a single trajectory with the shortest arrival time was calculated (the shortest trajectory) and the trajectory with the least amount of precipitation along the trajectory on the way to the receptor grid (the driest trajectory, possibly with precipitation only at receptor point). These trajectories were potential candidates for meteorological worst-case scenarios. All the statistics from Table 2 were shown in the Figure 6. 

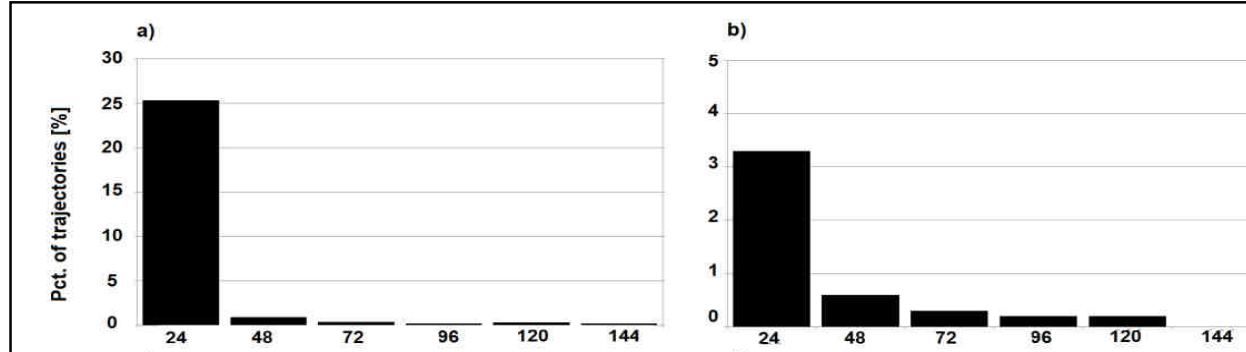

$$
\text { c) }
$$

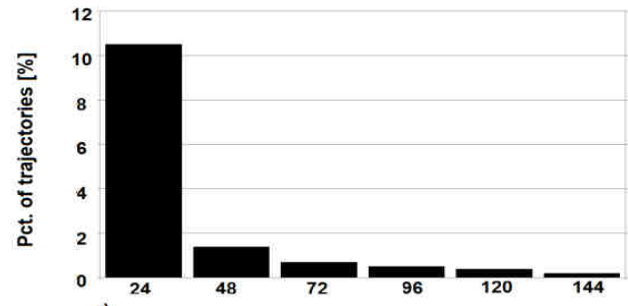

d)
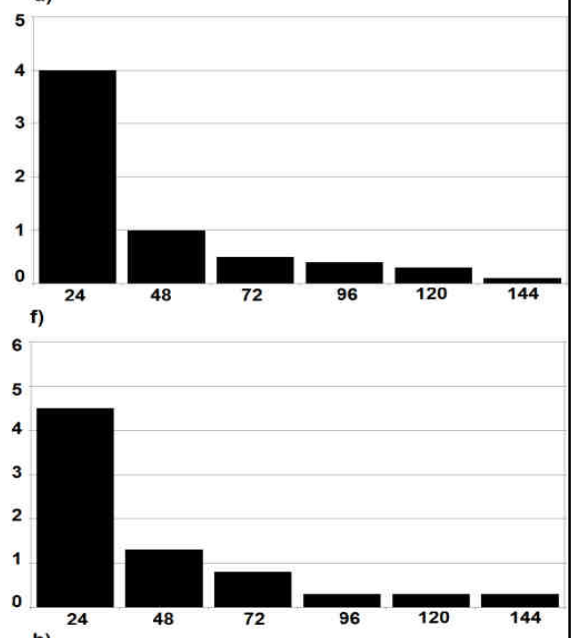

g)

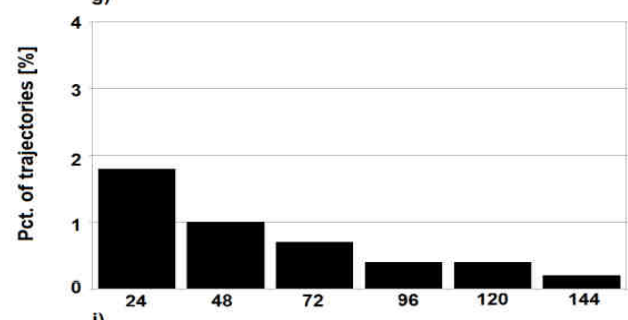

i)

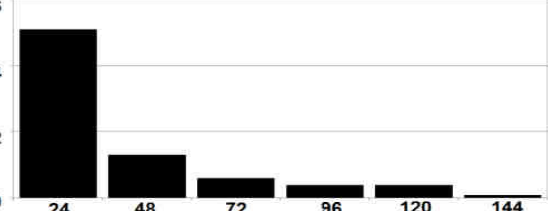

h)
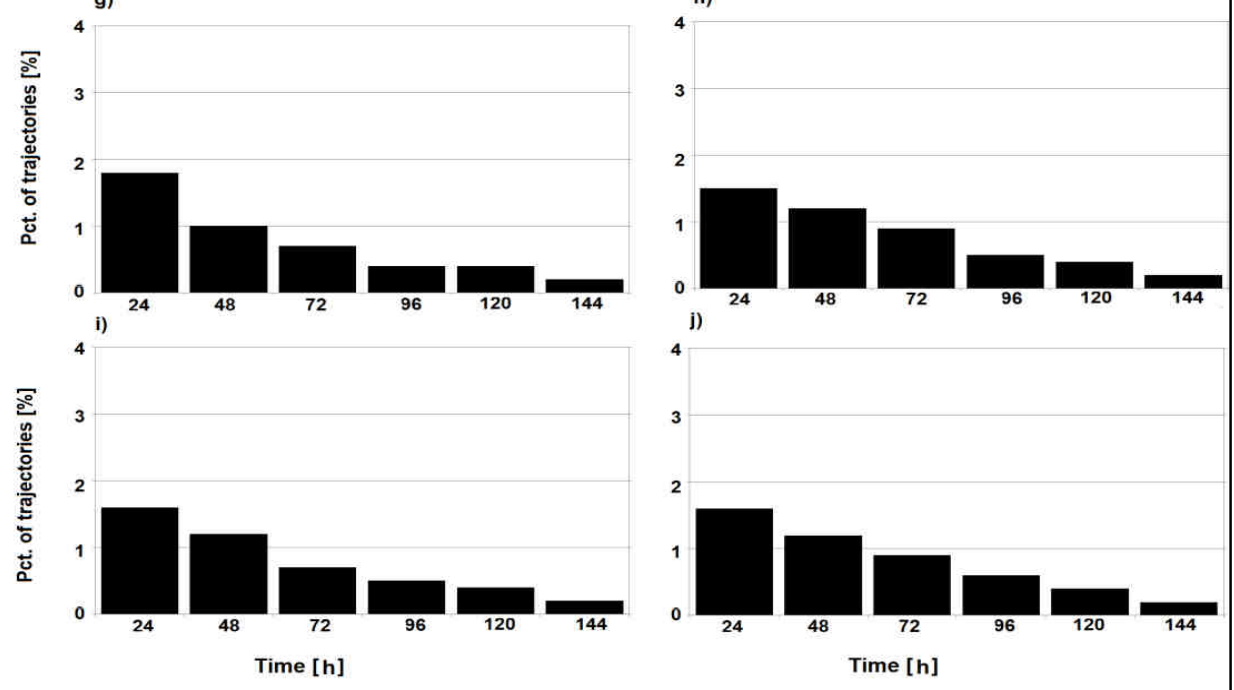

Fig. 6. Statistics of trajectories arriving to: a) Gdansk, b) Szczecin, c) Olsztyn, d) Poznan, e) Warszawa, f) Lodz, g) Wroclaw, h) Katowice, i) Krakow and j) Rzeszow - probability (percent) distribution for the arrival time to selected Polish cities. Every of six classes corresponds to transport period in days. $X$ axis - maximum time of trajectory arrival, $Y$ axis - percent of total amount of trajectories (see also explanation in text) 


\section{Selection of worst case meteorological scenarios}

As an immediate result of the first phase of the study, the shortest trajectories to the selected cities were found as the candidates for the worst case(s) scenarios from the meteorological point of view. As it was stressed, if an accident at Zarnowiec NPP happened under these sets of conditions, the time to prepare (needed for any countermeasures to be executed immediately) would be extremely short, especially, of course, for cities like Gdansk or Olsztyn. Nevertheless, other cities of interest would be in a similar situation and underneath of similar stress. Moreover, with the ETA (Estimated Time of Arrival) from source to any receptor point less than six hours, a presence of precipitation along a trajectory essentially could not change the intensity of impact. In other words, even if it rained between source and receptor and contamination was removed (to some extent) from the air to the ground, an amount of radioactive pollution at the final (receptor) stage of trajectory would be still very large.

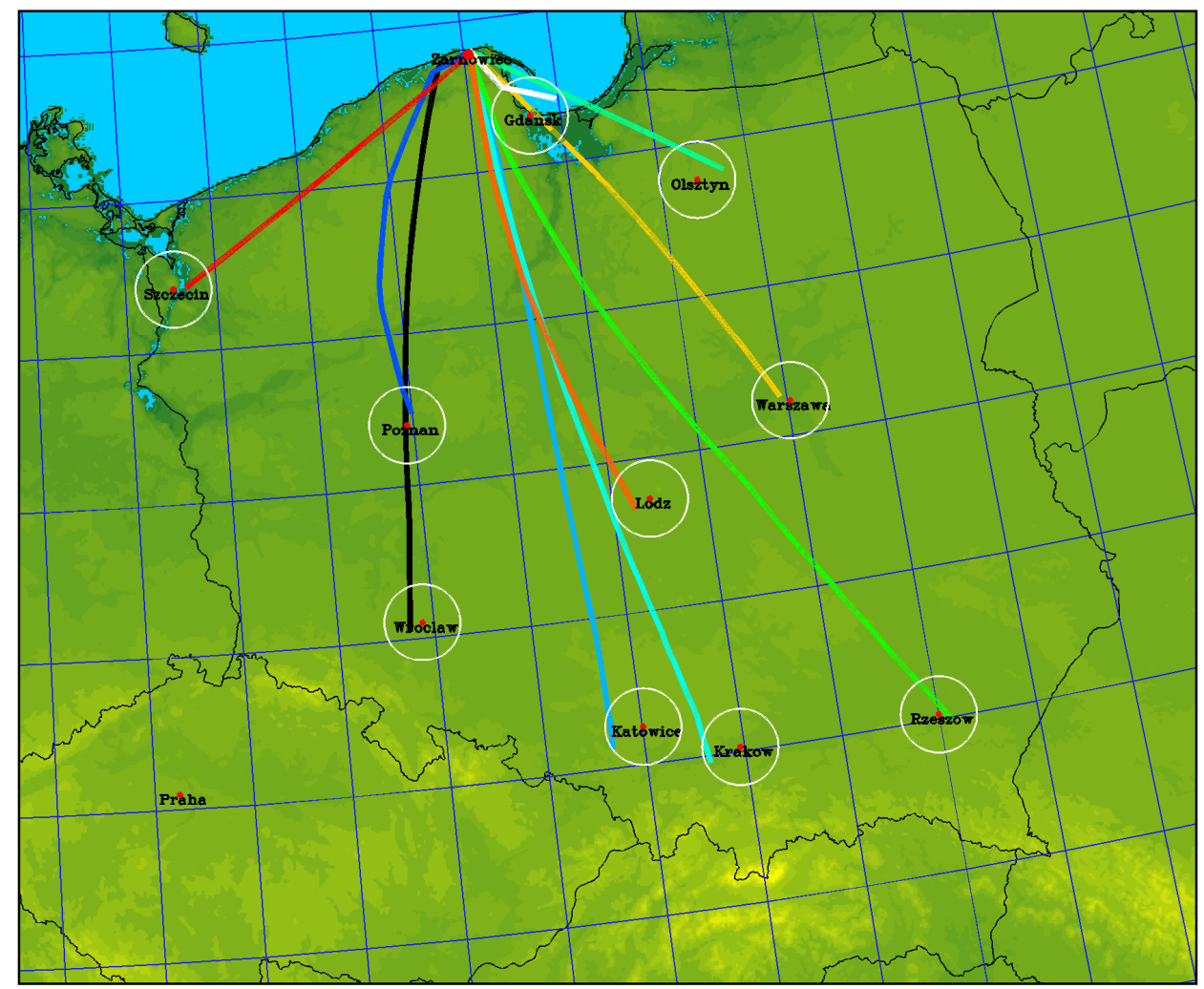

Fig. 7. Trajectories with the shortest ETA (fastest trajectories) from Zarnowiec NPP to each selected city (Gdansk, Szczecin, Olsztyn, Poznan, Wroclaw, Warszawa, Lodz, Krakow, Katowice, Rzeszow) in Poland (see Table 3 for details and explanations in text). Circles represent a "vulnerability" area around every receptor city

Another situation being a type of "candidate" for the worst case scenario for Poland as a whole would be the one presented in Figure 2, when a single trajectory travelled over 
Poland for almost ten days (i.e. during its entire "lifetime"). This kind of situation would result in a gradual "discharge" of a whole contamination load, carried by air parcel connected to the trajectory, to the ground via dry and (in case of occurrence of a precipitation) wet deposition. This scenario can be applied to not only the area of the entire Polish territory, but also to the urban areas of the cities of interest, assuming - for every city - a "vulnerability" area as a circle with a diameter of $60 \mathrm{~km}$. The situations described above are depicted in Figures 2, 7 and 8. The longest trajectory travelling over Poland is shown in Figure 2, while the shortest (the fastest) trajectories arriving to the cities of interest are shown in Figure 7. The examples of trajectories with the longest "impact time" for selected cities are shown in Figure 8, where the black part(s) of trajectory reflect an influence on a particular city. Similar results were obtained for all other receptor cities.

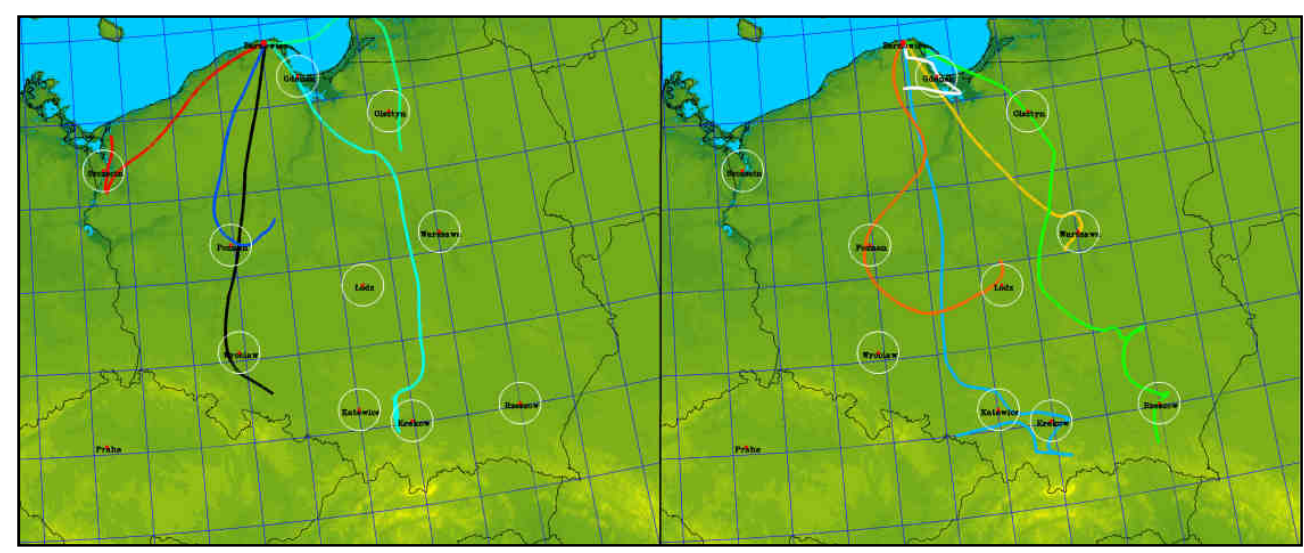

Fig. 8. Left: the trajectories with the longest "impact time" to Szczecin (red), Poznan (dark blue), Wroclaw (black), Olsztyn (light green) and Krakow (cyan); right: the trajectories with the longest "impact time" to Lodz (orange), Katowice (light blue), Rzeszow (green), Gdansk (white) and Warszawa (yellow). See Table 3 for details

Date and time of start of special trajectory (fastest or longest), line color in Figure 7

\begin{tabular}{|c|c|c|c|}
\hline Receptor city & $\begin{array}{c}\text { Start of fastest trajectory } \\
\text { (date, time) }\end{array}$ & $\begin{array}{c}\text { Line color in } \\
\text { Figure 7, 8 }\end{array}$ & $\begin{array}{c}\text { Start of longest trajectory } \\
\text { (date, time) }\end{array}$ \\
\hline Katowice & $16.01 .2008,06: 00$ & light blue & $24.08 .2011,00: 00$ \\
Szczecin & $04.01 .2008,06: 00$ & red & $27.07 .2014,00: 00$ \\
Rzeszow & $03.12 .2007,06: 00$ & green & $26.05 .2005,06: 00$ \\
Gdansk & $07.01 .2005,18: 00$ & white & $02.08 .2012,00: 00$ \\
Poznan & $29.09 .2007,12: 00$ & dark blue & $21.05 .2007,18: 00$ \\
Wroclaw & $27.04 .2009,00: 00$ & black & $19.06 .2013,00: 00$ \\
Olsztyn & $07.03 .2008,12: 00$ & light green & $06.06 .2014,12: 00$ \\
Lodz & $03.02 .2010,00: 00$ & orange & $15.10 .2012,12: 00$ \\
Krakow & $04.11 .2013,18: 00$ & cyan & $02.07 .2013,12: 00$ \\
Warszawa & $31.10 .2006,18: 00$ & yellow & $27.05 .2005,06: 00$ \\
\hline Poland & n/a* & red/black & $29.07 .2012,00: 00$ \\
\hline
\end{tabular}

"not applicable 


\section{Results - Eulerian dispersion modeling for worst cases scenarios}

All the cases listed above were during the second part of investigation studied with Eulerian dispersion model [5]. Assumptions of emission height and time were similar as the ones for trajectory analysis. However, contrary to trajectory method, when an emission height was fixed at one particular level $(925 \mathrm{hPa})$, in the Eulerian approach it was assumed that the emission was distributed with height using vertical profile like in Figure 9. It was due to the assumption that the total emission consisted mainly of hot light particles with high buoyancy close to the source, with the tendency to disperse rather up than down, somewhat (qualitatively) similar to the sulfur/water vapor emission from a volcano eruption (see e.g. $[11,12])$. The other generalization was not to simulate varying emission height profiles [13]. Total activity accepted for a single release was comparable to the one assumed in the Chernobyl [14] or in the Three Mile Island [15] accidents, and equal to $10^{18} \mathrm{~Bq}$. The total time span of a single emission episode was taken as equal to 3 hours, and after that the release was instantaneously cut off. This type of accident is similar to the Three Mile Island (where emission lasted for approx. sixteen hours) rather than the Chernobyl (ten days).

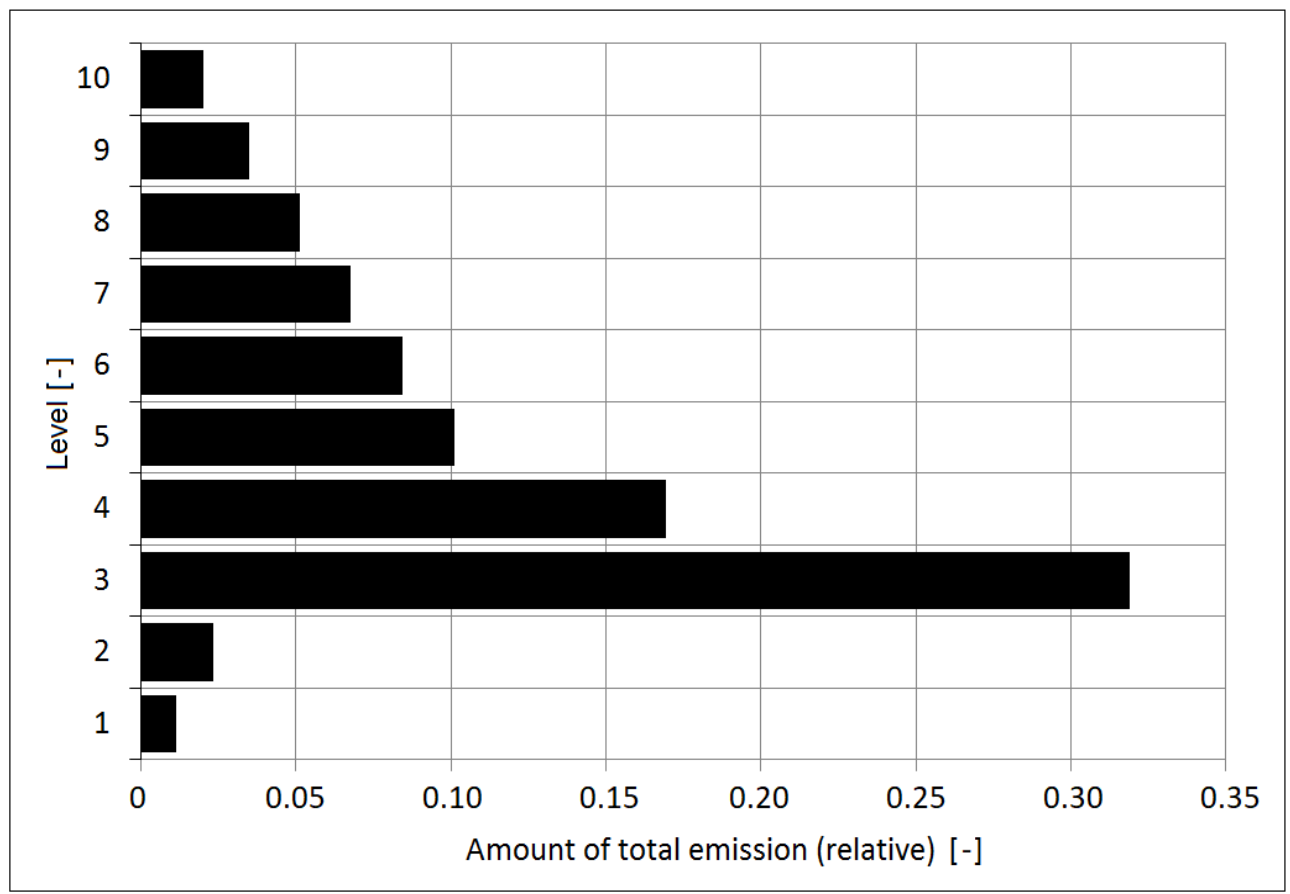

Fig. 9. Emission height profile. $Y$ axis - height level (1 to 10) as defined in Methodology, step 1; $X$ axis relative value of emission at given level (with grand total equal to 1)

As the second part of the study the worst case scenarios, assessed with Eulerian approach, are presented (cf. Figures 2, 7 and 8 with an explanation). First, in Figure 10 results of simulation of the case with the emission started July $29^{\text {th }}, 2008$, when trajectory released from Zarnowiec NPP has the longest travel time over Polish territory is shown. All 
the figures present results of the calculations of the Eulerian model with total activity treated as dispersing pollution. Next, the deposition patterns of nuclear pollution as the results of releases starting from dates specified in Table 3 are presented in Figures 11-13. These are the results for Eulerian model calculations in cases of "fastest trajectories" (cd. Fig. 7 and Table 3) for Katowice and Szczecin (Fig. 11), Rzeszow and Gdansk (Fig. 12), Poznan and Wroclaw (Fig. 13), Olsztyn and Lodz (Fig. 14), Krakow and Warszawa (Fig. 15).

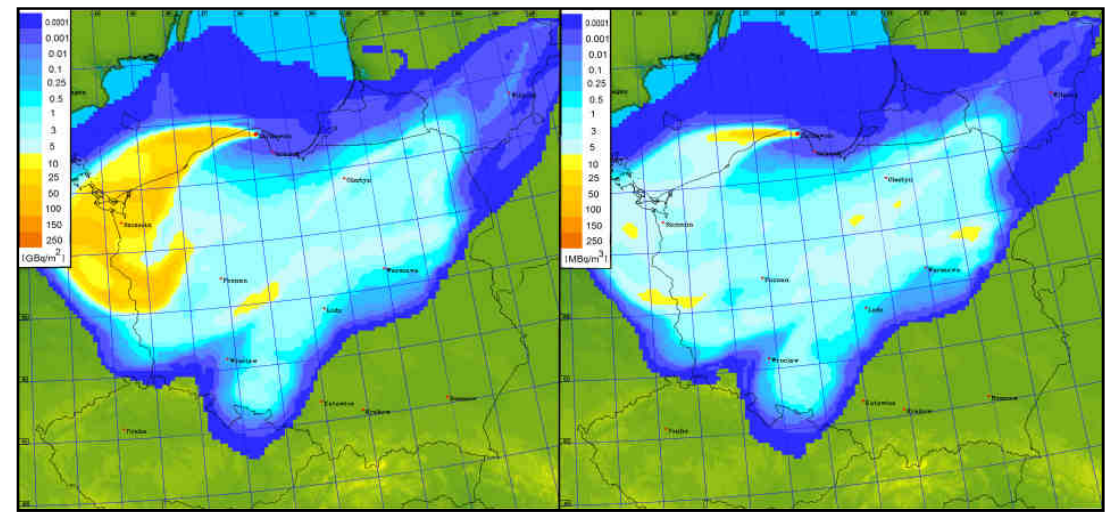

Fig. 10. Maps of the total deposition (left) and the average surface concentration (right), calculated for emission started July $29^{\text {th }}, 2008$, when trajectory released from Zarnowiec NPP has the longest travel time over Polish territory (ten days from the start; cf. explanation to Figure 7)

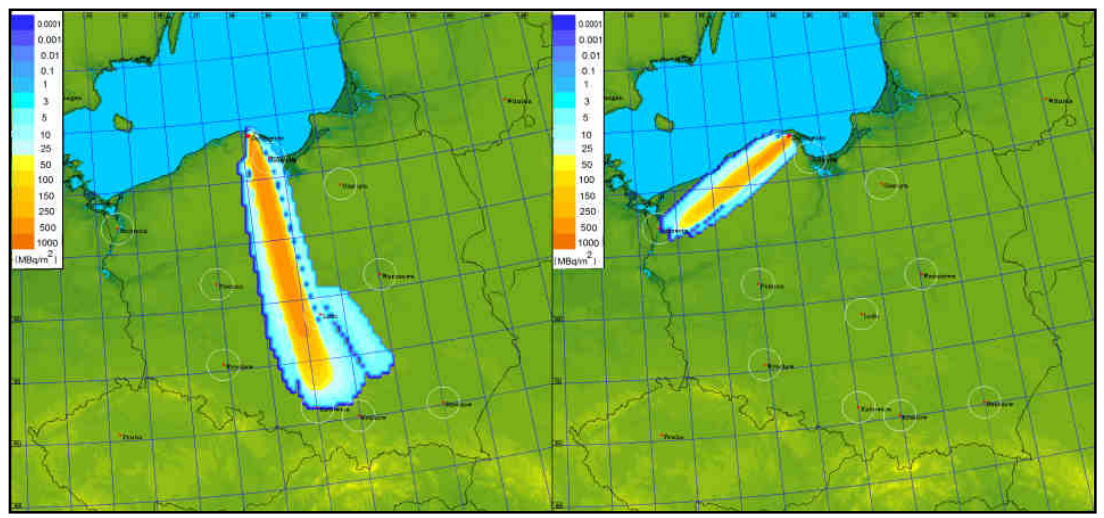

Fig. 11. Maps of the total deposition for the releases of "fastest trajectory" to Katowice (left, release started January $16^{\text {th }}, 2008$ ) and Szczecin (right, release started January $4^{\text {th }}, 2008$ )

Finally, the simulation results of deposition of contaminant for the releases with the longest "impact time" to receptor cities are presented in the following Figures 16-20 with the same sequence as for Figures 11-15 (cf. Fig. 8 and Table 3). 


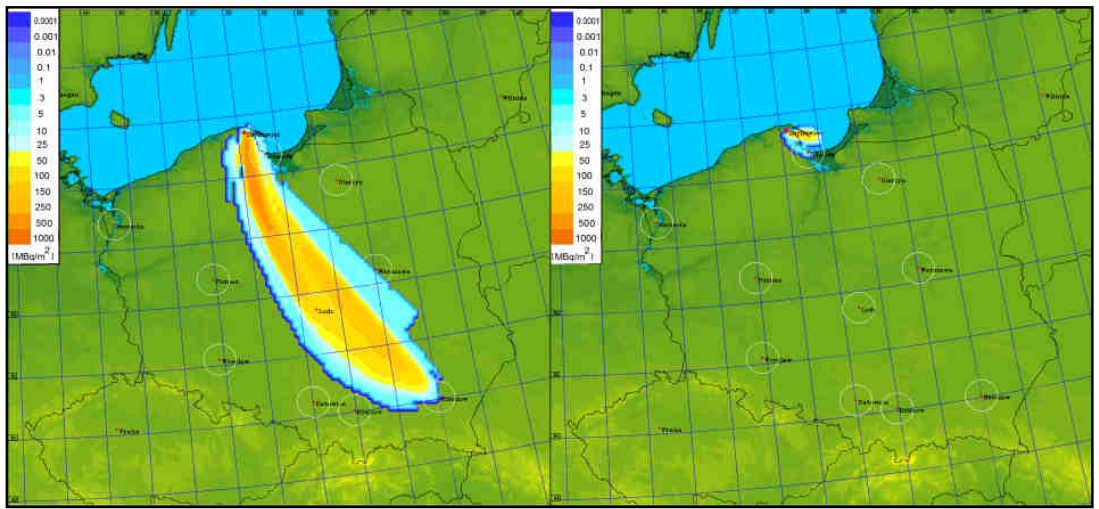

Fig. 12. Maps of the total deposition for the releases of "fastest trajectory" to Rzeszow (left, release started December $3^{\text {rd }}, 2007$ ) and Gdansk (right, release started January $7^{\text {th }}, 2005$ )

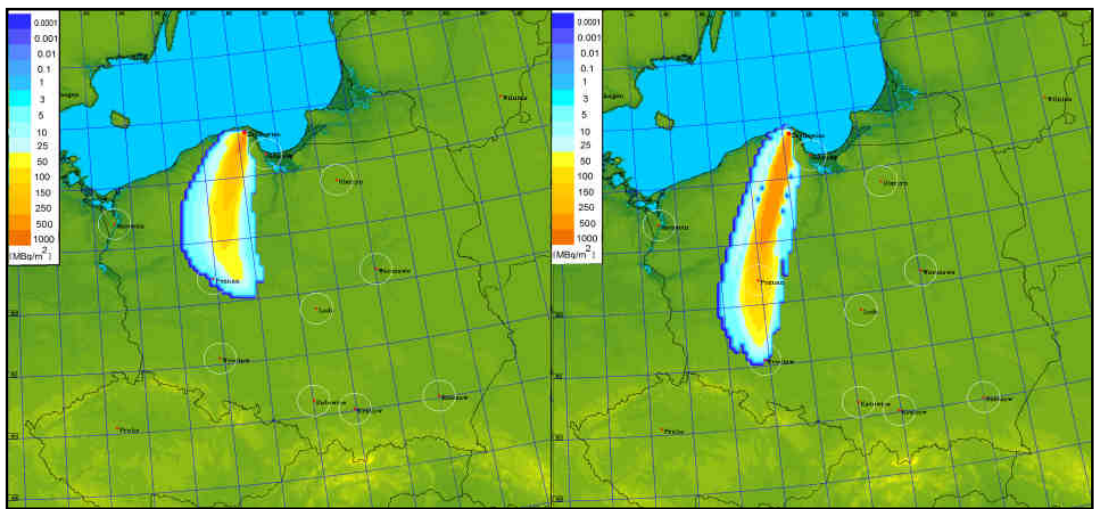

Fig. 13. Maps of the total deposition for the releases of "fastest trajectory" to Poznan (left, release started September $29^{\text {th }}, 2007$ ) and Wroclaw (right, release started April $27^{\text {th }}, 2009$ )

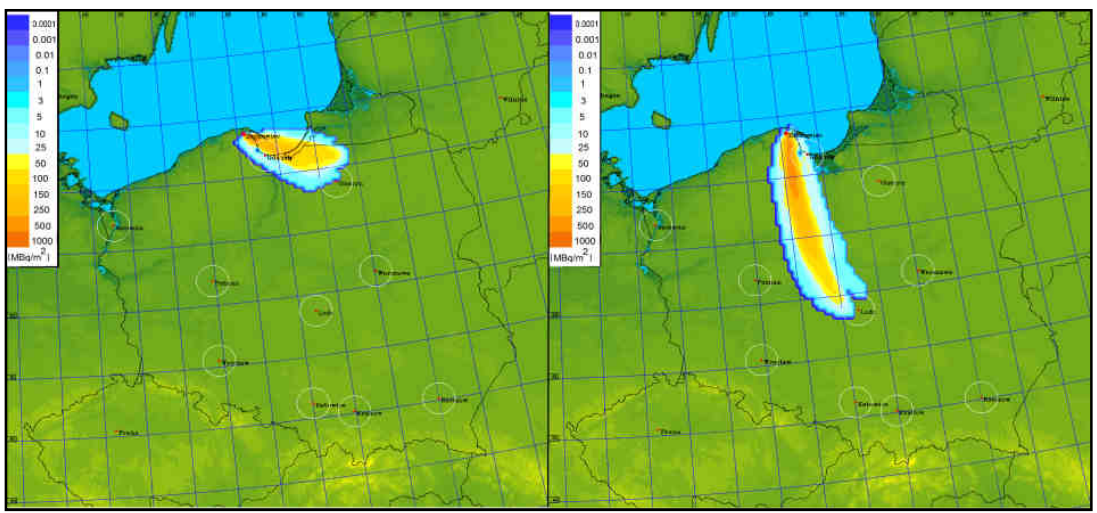

Fig. 14. Maps of the total deposition for the releases of "fastest trajectory" to Olsztyn (left, release started July $3^{\text {rd }}, 2008$ ) and Lodz (right, release started February $3^{\text {rd }}, 2010$ ) 


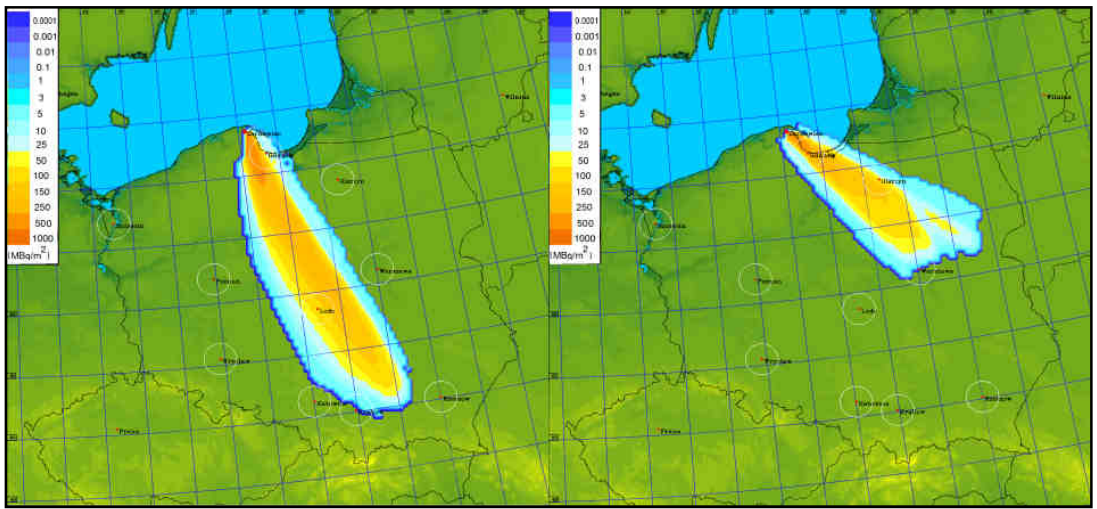

Fig. 15. Maps of the total deposition for the releases of "fastest trajectory" to Krakow (left, release started November $4^{\text {th }}, 2013$ ) and Warszawa (right, release started October $31^{\text {st }}, 2006$ )

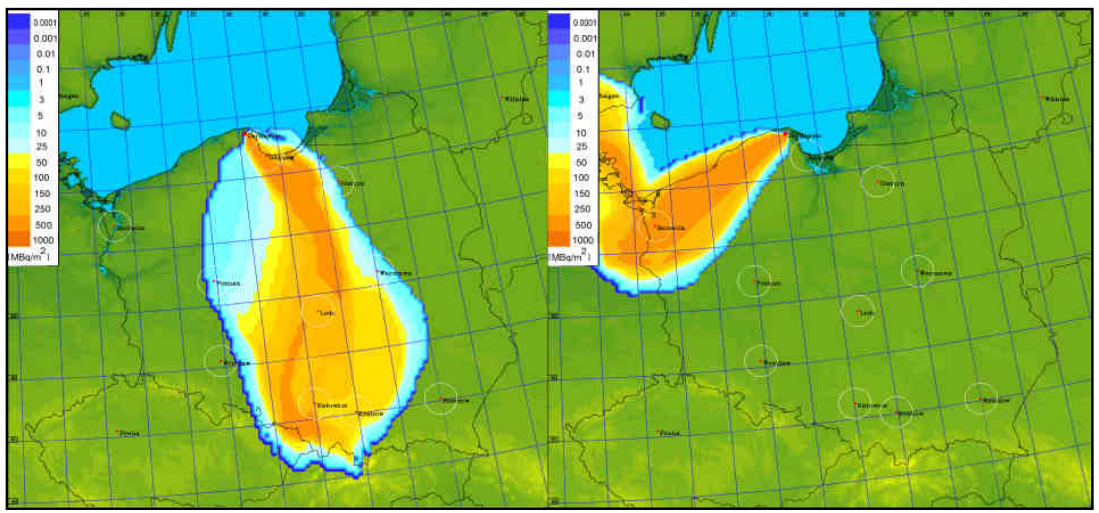

Fig. 16. Maps of the total deposition for the releases with the longest "impact time" to Katowice (left; release started August $24^{\text {th }}, 2011$ ) and Szczecin (right; release started July $27^{\text {th }}, 2014$ )

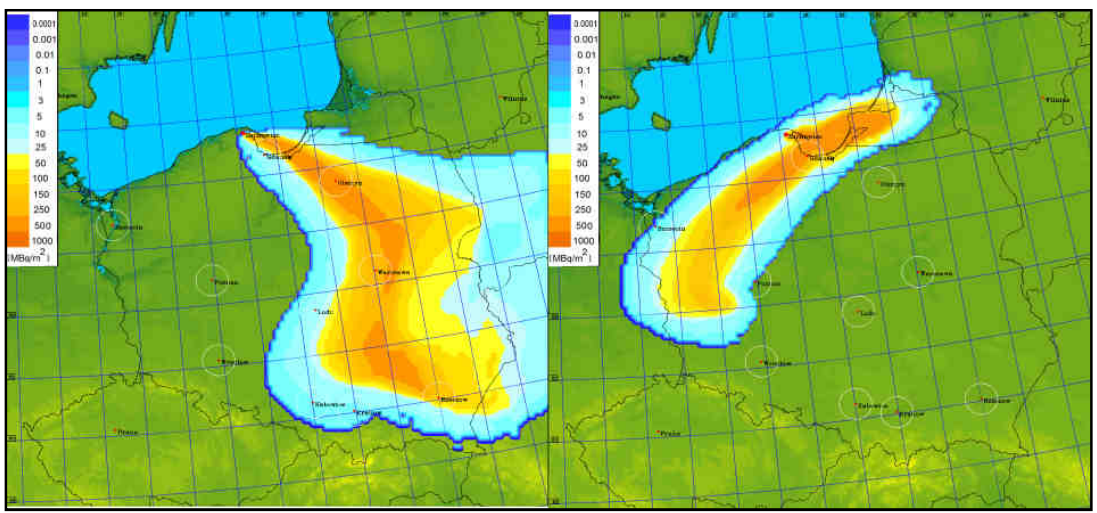

Fig. 17. Maps of the total deposition for the releases with the longest "impact time" to Rzeszow (left, release started May $26^{\text {th }}, 2005$ ) and Gdansk (right, release started August $2^{\text {nd }}, 2012$ ) 


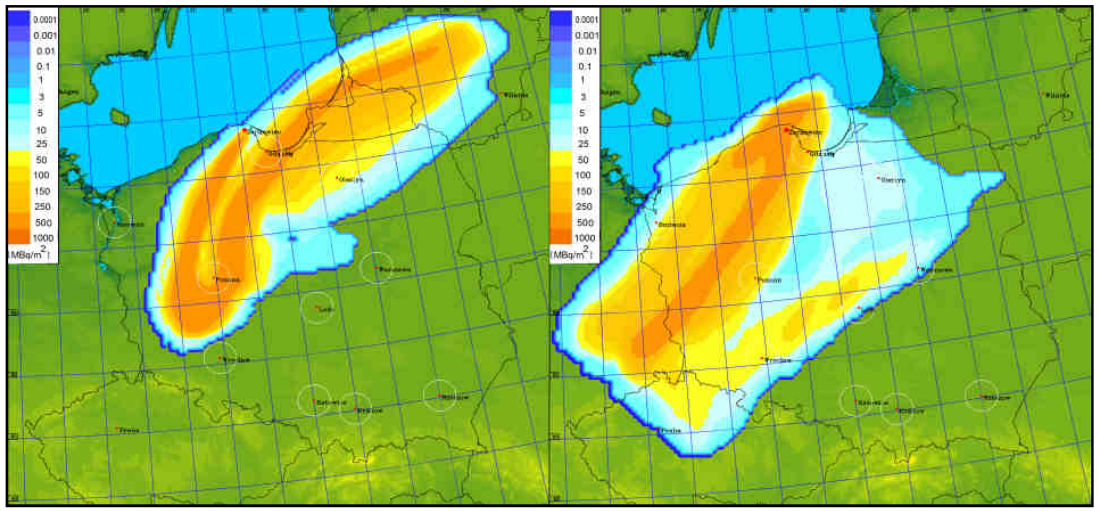

Fig. 18. Maps of the total deposition for the releases with the longest "impact time" to Poznan (left, release started May $21^{\text {st }}, 2007$ ) and Wroclaw (right, release started June $19^{\text {th }}, 2013$ )

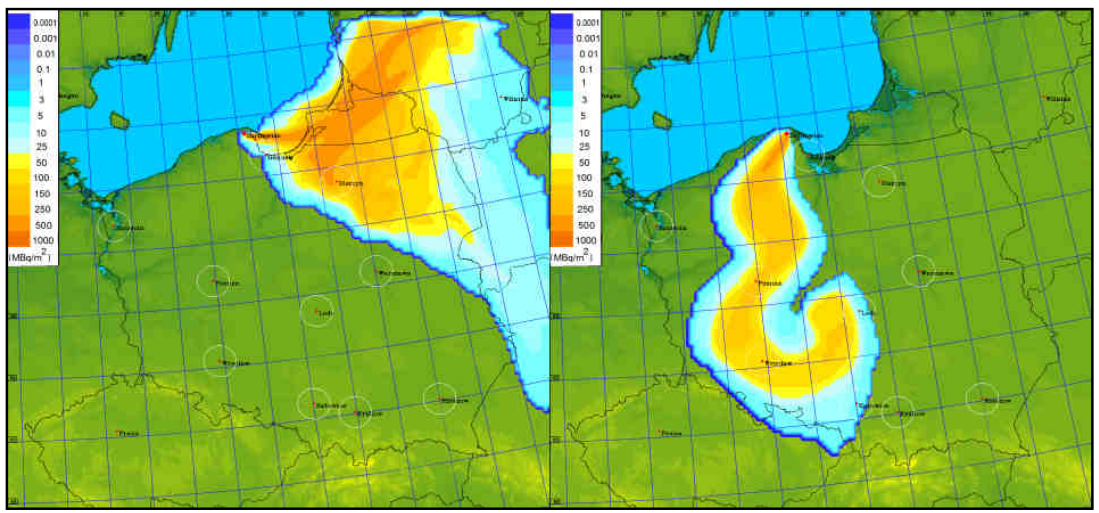

Fig. 19. Maps of the total deposition for the releases with the longest "impact time" to Olsztyn (left, release started June $6^{\text {th }}, 2014$ ) and Lodz (right, release started October $15^{\text {th }}, 2012$ )

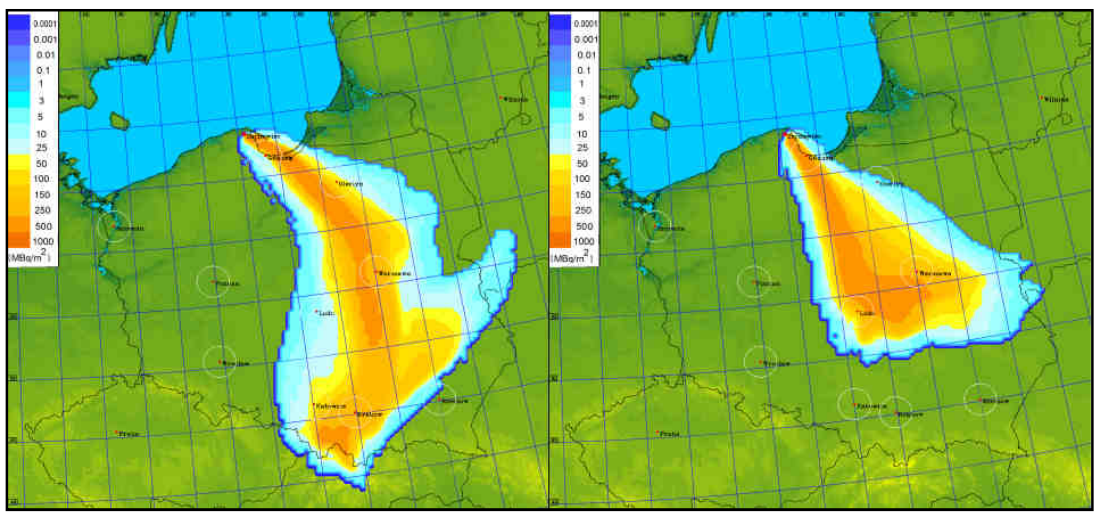

Fig. 20. Maps of the total deposition for the releases with the longest "impact time" to Krakow (left, release started July $2^{\text {nd }}, 2013$ ) and Warszawa (right, release started May $27^{\text {th }}, 2015$ ) 


\section{Discussion}

The aim of this study was the selection of the worst case meteorological scenarios for Poland and Polish cities in case of hypothetical accident in Zarnowiec NPP. First, climatological three-dimensional trajectory analysis was applied in order to estimate probabilities of the arrival of a radioactive cloud to selected Polish cities, then the shortest and average transport time was calculated and finally the worst case scenarios were selected. The results of the climatologic trajectory analysis show that the probability of a radioactive cloud reaching any city in case of an accident in Zarnowiec NPP is closely related, first, to distance between source and a receptor city, and second, to a location of receptor city relative to the source (in terms of azimuth/direction from the source to a receptor). The second factor is due to the fact that - climatologically speaking - the prevailing wind directions over Poland are southern and southwestern. The relation between travel time, probability of arrival and distance from source to receptor is not that obvious. For example, identical distances from Zarnowiec to Poznan and to Szczecin are not necessarily reflected in same statistics for these receptors. It is most likely correlated to predominant wind directions over Poland for the period of study, when north-eastern winds appeared much more often than eastern ones. So, if the distance from Zarnowiec NPP to Szczecin is equal to the distance to Poznan, yet, Szczecin is located roughly west of Zarnowiec NPP, while Poznan - south-south-west, hence this implied the probability of an impact on Szczecin significantly lower than that on Poznan.

What should be underlined is that the minimum time for almost all points in Poland (and all cities selected in this study) is shorter than 6 hours. So the preparation time in strong unfavorable conditions could be enormously short. In case of Gdansk (with a total population of almost half a million people), this time is about several minutes, which would make a preparation extremely difficult and demanding.

Another type of scenario to be evaluated in the second part of the study would be trajectory, released at the source and travelling to a receptor point and then becoming almost "inert", i.e. slowing its movement over an agglomeration, causing lengthened deposition and thus an impact to a receptor. In the extreme case this prolongation could reach few hours.

The third kind of worst-case scenario - in term of the entire Polish territory would be a trajectory that "stayed" over Poland for a very long time - for the same reasons as mentioned above. In the study it was possible to find this kind of trajectory that lasted for ten days (i.e., the entire lifetime of trajectory).

These worst-case scenarios was studied thoroughly in the second phase of the study.

Incidentally, it should be stressed again, that contrary to trajectory method, when an emission height was fixed at one particular level $(925 \mathrm{hPa})$, in the Eulerian approach an emission was assumed to consist of hot and light particles with high buoyancy, especially close to the source. Thus, the entire amount of emitted contamination cloud was distributed over a height profile, similar to the profile of sulfur emission from a volcano eruption. Hence, even though a trajectory and field approach (i.e., Lagrangian and Eulerian, respectively) would have resulted in a qualitatively similar spatial distribution pattern of area(s) under impact, quantitative discrepancies (in terms of absolute values of deposition and/or concentration) may be seen. This kind of comparison, however, will be a subject of separate research. 
In general, the main finding (regrettably for receptor cities) remains unchanged. It means that time for preparation and countermeasures to be taken is fairly short. This pertains especially to Gdansk (with its entire conurbation) and a population of almost half a million. Of course, since ETAs are relatively short, most of material emitted remains most likely - in the cloud dispersing over a receptor point. So, the deposition to the ground can be reasonably high, especially in the form of washout with precipitation.

Considering the potential release of July $29^{\text {th }}, 2008$, when trajectory released from Zarnowiec NPP has the longest travel time (10 days from the start, see explanation to Fig. 2) over Poland, it would result in a quite disastrous situation, when more than $75 \%$ of total activity emitted from the source would be deposited to the ground (or would form a radioactive cloud in the air) over the Polish territory. Even short release (three hours from start to cut-off) would generate contamination comparable to the one from the Chernobyl accident rather to the Three Mile Island release, since the meteorological conditions would have supported wide dispersion of contaminants in a range of several hundreds of kilometers. This kind of impact would be similar for releases that would result in a radioactive cloud staying for a relatively long time over selected receptor points (compare e.g. Figs. 8 and 12). Of course, the longer radioactive cloud stayed over a city, the bigger amount of contaminant would impact the receptor. It's due to the fact, that after a relatively short time of dispersion (travel), the amount of contamination in the cloud would be high enough to have a substantial impact on the receptor point and its vicinity in terms of absolute value of deposition and cloud concentration of pollution. However, even if total deposition was high before selected point was "hit" by the cloud, it was still enough contamination to impact the city significantly. Overall, two concurrent actions could be observed as far as a "long impact" phenomenon is concerned. First one, already mentioned above, is that the contaminant released as a pollution cloud is travelling to a receptor point and then significantly slowing its movement over an agglomeration causing deposition being prolonged in time. This kind of action was observed in the case of Poznan, Rzeszow and Wroclaw (cf. Fig. 15) and Warszawa and Lodz (Fig. 16). The other mechanism is that cloud (not necessarily slowed down) is turning and changing a direction of its movement over the vicinity of a receptor point - even many times, still remaining in a "vulnerability area". This effect can be seen for other receptor points. Sometimes, both mechanisms can be observed simultaneously, in a synergistic way creating more noticeable impact.

\section{Conclusions}

A hypothetical accident in any NPP outside Polish territory can affect Poland in a very serious way. As a very recent history showed, nuclear accidents might indeed occur and they were not only hypothetical. Polish Ministry of Energy is planning an NPP to be located in Poland in Zarnowiec, close to the city of Gdansk with the population of about the half of million people. The worst case scenarios showed that in case of accident in such a NPP the time needed to prepare and to react would be very short. This supposition seems to be valid using the results both from Lagrangian and from Eulerian approach of simulation of dispersion of radioactive pollutants. Moreover, the results strongly suggest that there is a need for system to respond to an occurrence of an emergency situation(s), and to provide support for information about the further development of events, with the forecast the status of the environment and the possibility of negative impact on human 
communities. A proper decision support system (see eg. [16]) should be considered as one of such tools, the use of which would be solely for the benefit of the many areas of social activities.

\section{References}

[1] Bartnicki J, Saltbones J. Analysis of Atmospheric Transport and Deposition of Radioactive Material Released during a Potential Accident at Kola Nuclear Power Plant. Research Report No. 43, Oslo, Norway: Norwegian Meteorological Institute; 1997. ISSN: 03329879. https://link.springer.com/content/pdf/10.1007/978-1-4615-4153-0_57.pdf.

[2] Mahura AG, Baklanov AA, Sorensen JH. Estimation of potential impact on Copenhagen, Denmark due to accidental releases at Nuclear Risk Sites. Int J Environ Pollut. 2009;39(1-2):159-167. DOI: 10.1504/IJEP.2009.027149.

[3] Bergman R, Baklanov A, Segerstahl B. Overview of Nuclear Risks on the Kola Peninsula. IIASA Policy Report. XQ-96-806. Laxenburg, Austria: IIASA; 1996. http://pure.iiasa.ac.at/4796.

[4] Mahura AG, Andres R, Jaffe D. Atmospheric Transport Patterns from the Kola Nuclear Reactors. CERUM Northern Studies No. 24. Umea, Sweden: Umea University; 2001. http://www.cerum.umu.se/digitalAssets/34/34120_ns_24_01a1.pdf.

[5] Mazur A, Bartnicki J, Zwoździak J, Operational model for atmospheric transport and deposition of air pollution. Ecol Chem Eng S. 2014;21(3):385-400. DOI: 10.2478/eces-2014-0028.

[6] Nordlund G, Rossi J, Valkama I, Vuori S. Probabilistic trajectory and dose analysis for Finland due to hypothetical radioactive release at Sosnovy Bor. Research Note 847. Espoo, Finland: Technical Research Centre of Finland; 1998. ISBN: 951383106.

[7] Schaettler U, Blahak U. A Description of the Nonhydrostatic Regional COSMO-Model. Part V: Preprocessing: Initial and Boundary Data for the COSMO-Model. 2017. http://www.cosmo-model.org/ content/model/documentation/core/int2lm_2.05.pdf.

[8] Schaettler U, Doms G., Schraff C. A Description of the Nonhydrostatic Regional COSMO-Model. Part VII: User Guide, 2016. http://www.cosmo-model.org/content/model/documentation/core/ cosmo_userguide_5.04.pdf.

[9] Pongkiatkul P, Kim Oanh NT. Assessment of potential long-range transport of particulate air pollution using trajectory modeling and monitoring data. Atmos Res. 2007;85:3-17. DOI: 10.1016/j.atmosres.2006. 10.003.

[10] Draxler RR. Demonstration of a global modeling methodology to determine the relative importance of local and long-distance sources. Atmos Environ. 2007;41:776-789. DOI: 10.1016/j.atmosenv.2006.08.052.

[11] Eckhardt S, Prata AJ, Seibert P, Stebel K, Stohl A. Estimation of the vertical profile of sulfur dioxide injection into the atmosphere by a volcanic eruption using satellite column measurements and inverse transport modeling. Atmos Chem Phys. 2008;8:3881-3897. DOI: 10.5194/acp-8-3881-2008.

[12] Carboni E, Grainger RG, Mather TA, Pyle DM, Thomas GE, Siddans R, et al. The vertical distribution of volcanic SO2 plumes measured by IASI. Atmos Chem Phys. 2016;16:4343-4367. DOI: 10.5194/acp-16-4343-2016.

[13] Christoudias T, Proestos Y, Lelieveld J. Atmospheric dispersion of radioactivity from nuclear power plant accidents: Global assessment and case study for the Eastern Mediterranean and Middle East. Energies. 2014; 7:8338-8354. DOI: 10.3390/en7128338.

[14] Gudiksen PH, Harvey TF, Lange R. Chernobyl source term, atmospheric dispersion, and dose estimation. Health Phys. 1989;57(5):697-706. DOI: 10.1097/00004032-198911000-00001.

[15] Mangano J. Three Mile Island: Health Study Meltdown. Bull Atomic Sci. 2004;60(5):30-35. DOI: $10.2968 / 060005010$.

[16] Mazur A. Project RIOT - Ring of Threats - as an example of Decision Support System (DSS). Concept and realization. Meteorol Hydrol Water Manage. 2015;3(2): 39-47. DOI: 10.26491/mhwm/60273. 